\title{
Robotic esophagectomy: the evolution of open esophagectomy to current techniques and a review of the literature
}

\author{
Rian M. Hasson ${ }^{1,2,3}$, Kayla A. Fay ${ }^{2}$, Joseph D. Phillips ${ }^{1,3}$, Timothy M. Millington ${ }^{1,3}$, David J. Finley ${ }^{1,3}$ \\ 'Dartmouth-Hitchcock Medical Center, Department of Surgery, Section of Thoracic Surgery, Lebanon, NH 03766, USA. \\ ${ }^{2}$ The Dartmouth Institute of Health Policy and Clinical Practice, Lebanon, NH 03766, USA. \\ ${ }^{3}$ Geisel School of Medicine, Hanover, NH 03755, USA.
}

Correspondence to: Dr. Rian M. Hasson, Department of Surgery, Section of Thoracic Surgery, The Dartmouth Institute of Health Policy and Clinical Practice, Dartmouth-Hitchcock Medical Center, 1 Medical Center Drive, Lebanon, NH 03766, USA.

E-mail: rian.m.hasson@hitchcock.org

How to cite this article: Hasson RM, Fay KA, Phillips JD, Millington TM, Finley DJ. Robotic esophagectomy: the evolution of open esophagectomy to current techniques and a review of the literature. Mini-invasive Surg 2020;4:46.

http://dx.doi.org/10.20517/2574-1225.2020.10

Received: 14 Jan 2020 First Decision: 19 Feb 2020 Revised: 30 Mar 2020 Accepted: 30 Apr 2020 Published: 26 Jul 2020

Science Editor: Noriyoshi Sawabata Copy Editor: Jing-Wen Zhang Production Editor: Tian Zhang

\begin{abstract}
Esophageal cancer persists as one of the most common causes of cancer-related death and 5-year survival remains poor at $20 \%$. Surgical resection is the gold standard for treatment and cure, and the development of minimally invasive surgery has increased the popularity of robotic-assisted minimally-invasive esophagectomy. The benefits described include less morbidity and greater patient satisfaction compared to open techniques. Nevertheless, institution capabilities and surgeon experience are strong determinants of whether a robotic program will be adopted for oncologic esophageal care. Thus, we review the available literature regarding the history of esophagectomy, evolution to minimally invasive approaches, the introduction of robotic-assisted esophagectomy including its respective outcomes in comparison to open and minimally invasive approaches, and future directions.
\end{abstract}

Keywords: Minimally invasive, esophageal cancer, esophagectomy, lymph node dissection, robotic-assisted esophagectomy, Ivor Lewis, McKeown, transhiatal

\section{INTRODUCTION}

Globally, esophageal cancer is the eighth most common cancer in the world and the sixth most common cause of cancer death ${ }^{[1]}$. Despite many advances in treatment, 5-year survival remains poor at 15\%-25\%;

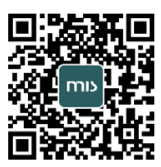


among all patients ${ }^{[2]}$, and the American Cancer Society estimates approximately 17,650 new esophageal cancer cases will be diagnosed in 2020 , with an estimated 16,170 cases resulting in death ${ }^{[3]}$. While esophageal resection, with or without neoadjuvant chemoradiation therapy, remains the most likely route of cure for these patients, less than $50 \%$ present with locoregional disease ${ }^{[4]}$, a prerequisite for surgical intervention ${ }^{[5]}$. Furthermore, despite the oncologic benefits, traditional open esophagectomy is associated with considerable morbidity and mortality, complication rates range from $26 \%$ to $41 \%$, with perioperative mortality as high as $4 \%-10 \%{ }^{[4-6]}$.

Fortunately, of those patients who are candidates, survival increases to $40 \%$ among patients who successfully undergo curative surgery ${ }^{[2]}$, and resection can also palliate the debilitating symptoms of dysphagia that often accompany the disease ${ }^{[7]}$. Hence, surgical resection remains the gold standard for cure and definitive symptom management. The choice of technique depends on several factors with the location of the tumor, an institution's resources, and surgeon experience being the most relevant ${ }^{[7]}$. Traditionally, open esophagectomy (OE), utilizing either a transthoracic (OTTE) or transhiatal (OTHE) approach has been the surgical treatment of choice with Ivor Lewis, via thoracotomy and laparotomy; McKeown via thoracotomy, laparotomy, and cervical incision; and Transhiatal via laparotomy and cervical incision comprising the standard methods of resection.

Minimally invasive techniques were introduced in the early 1990 s to help lessen the morbidity associated with this procedure and have increasingly become more common over the last 30 years $^{[5,8]}$. They were designed to decrease the high morbidity and mortality associated with open resection through utilization of a combination of laparoscopy and thoracoscopy ${ }^{[9]}$. Although multiple studies have demonstrated a decrease in perioperative complications, the data describing oncologic outcomes, specifically regarding the extent of lymph node dissection, are varied.

More recently, robotic-assisted minimally invasive esophagectomy (RAMIE) is an alternative to standard minimally invasive esophagectomy (MIE), and has been increasingly applied to the treatment of esophageal cancer $^{[10]}$. Its benefits include a superior quality $3 \mathrm{D}$ image and free articulation of the tips of the robotic instruments ${ }^{[10]}$ that can assist in more precise movements ${ }^{[10]}$, especially enhancing the lymph node dissections. More and more studies are demonstrating that robotic approaches to esophagectomy reduce morbidity and mortality, and patients report better overall quality of life, physical function, and less fatigue and pain at three months after surgery ${ }^{[11]}$. Nonetheless, while robotic-assisted esophagectomy is a promising procedure, technical difficulties, long operating times, and lack of experience make this procedure difficult to adopt for many hospitals ${ }^{[12]}$. Today, convincing data on how beneficial and to what extent RAMIE resection provides superior perioperative and oncologic outcomes, increased costeffectiveness, and improved quality of life remain unclear ${ }^{[5]}$. The aim of this work is to review the available literature regarding robotic-assisted esophagectomy and its origins; compare perioperative, oncologic, and quality of life outcomes with open and minimally invasive approaches; and explore future directions.

\section{MATERIALS AND METHODS}

A literature search was conducted in Medline (PubMed), which queried the keywords "Esophageal Cancer, Esophagectomy, Open Esophagectomy, MIE, RAMIE, Robotic Esophagectomy, Lymph Node Dissection, Ivor Lewis, McKeown, and Transhiatal Esophagectomy". All articles that were in the English language and discussed open, laparoscopic, thoracoscopic, combined approaches, and robotic-assisted techniques were reviewed. For data acquisition, articles were included if they met the above inclusion criteria and were comparative studies of minimally invasive and open esophageal resection, minimally invasive and robotic resection, open and robotic resection, or all three techniques with the goal to detail their historical development, contemporary outcomes and future directions. 


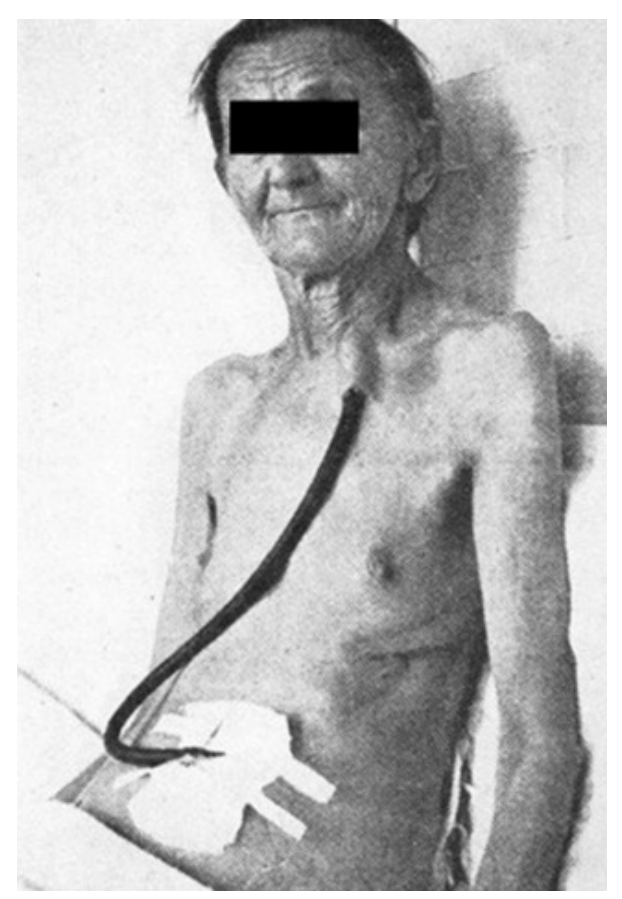

Figure 1. Torek Esophagectomy. Franz Torek first described resection of the thoracic esophagus using a rubber tube. Used with permission: The Annals of Thoracic Surgery 1965;4(85):1497-1499.

\section{RESULTS}

\section{History of esophagectomy and open techniques}

To better understand advancements in esophageal surgery, it is important to take a moment to review the history of esophageal resection and the complexities of this procedure. Ivor Lewis said it best when he stated, "there is little doubt that the successful outcome of curative surgery for esophageal carcinoma remains one of the great challenges of surgical practice". Historically, innovation drove many advancements in treatment of esophageal disease dating back to 1913. Franz Torek first described resection of the thoracic esophagus using a rubber tube to create an extra-anatomic reconstruction [Figure 1$]^{[8,13]}$.

Amazingly, the patient survived for 13 years, leading to the evolution of surgical procedures to resect the esophagus and replace it with a gastric conduit ${ }^{[14]}$. Subsequent versions have included the Ivor Lewis (IL) esophagectomy via right or left thoracotomy with subsequent two-field esophagectomy ${ }^{[15]}$; the McKeown esophagectomy involving a three-field esophagectomy with thoracotomy and laparotomy and terminating with a cervical anastomosis ${ }^{[16]}$; and Orringer and Sloan's transhiatal esophagectomy (THE), involving laparotomy and cervical anastomosis ${ }^{[17]}$.

The Achilles heel of esophageal cancer surgery has always been the high complication rates, even when performed at high-volume centers. Despite improvements over the years, the rates of morbidity and mortality of open esophagectomy remain high and are estimated to range 30\%-60\% and 5\%-10\%, respectively, depending on patient comorbidities and place of operation ${ }^{[8]}$. Mortality has been shown to decrease to $<5 \%$ in centers that perform more than 100 esophagectomies per year ${ }^{[8]}$. Although technical advances have improved the rate of anastomotic leak, consequences of a leak into the chest were and continue to be devastating and difficult to manage ${ }^{[18]}$. Notably, transhiatal esophagectomy has historically demonstrated reduced mortality rates from anastomotic leak resulting in less severe consequences compared to the IL approach, although it does have a higher overall leak rate. Meta-analysis has further demonstrated a mortality rate of $6.3 \%$ for transhiatal esophagectomy compared with $9.5 \%$ for the IL 


\section{Table 1. Laparoscopic, thoracoscopic and robotic approaches to esophagectomy by}

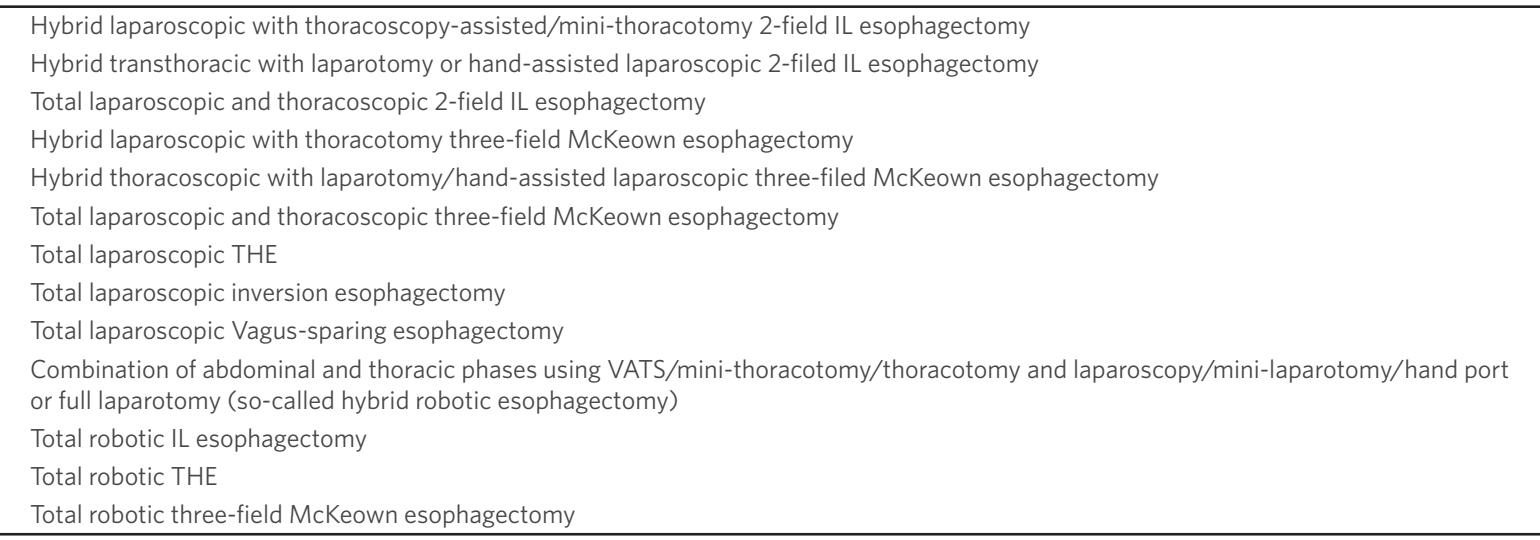

IL: Ivor Lewis; THE: transhiatal esophagectomy; VATS: video-assisted thoracoscopic surgery

approach $^{[18,19]}$. Unfortunately, in practice, this procedure is performed less often, which limits its benefit to the patient.

\section{Minimally invasive techniques}

High complication rates, longer recovery times, and the desire for a less invasive procedure is what led to the innovation driving minimally invasive surgery. Specifically for esophagectomy, the definition of a MIE includes varying thoracoscopic and laparoscopic approaches for esophageal resection based on the location of the tumor, clinical stage, and patient characteristics ${ }^{[20,21]}$. In 1991, Dallemagne et al ${ }^{[22]}$ first reported the use of laparoscopy for a hiatal hernia repair, inspiring Cuschieri et al. ${ }^{[23,24]}$ who utilized thoracoscopy for esophagectomy in 1992. In 1993, Collard et al. ${ }^{[25]}$ sophisticated the technique, and, in 1995, DePaula et al. ${ }^{[26]}$ was the first to perform a completely laparoscopic THE. Today, many different versions of MIE are performed ${ }^{[27]}$ employing several combinations of approach using laparoscopic and thoracoscopic techniques [Table 1, Items 1-9].

Indications for minimally-invasive esophageal resection approaches are similar to those for open esophagectomy and include esophageal cancer, failure of endoscopic ablation and/or resection for high grade dysplasia secondary to Barrett's esophagitis, stricturing of the esophagus, and the sequelae of achalasia and Chagas disease known as "burned out esophagus" ${ }^{\text {"27] }}$. Relative contraindications to its use are known extensive pleural or abdominal adhesions, with absolute contraindications involving the inability to use single-lung ventilation because of previous resection or poor lung function. As expected, surgeon comfort and experience have proven to be additional important factors.

Reviewing the operative steps of MIE, they are similar to robotic esophagectomy with the exception of port placement and can help to better define the benefits of robotic approaches. In general, the benefits have proven to be great. For minimally invasive IL esophagectomy, Levy et al ${ }^{[28,29]}$ and Luketich et al. ${ }^{[30]}$ best described the operative steps including commencing with an abdominal phase to mobilize the stomach/ proximal duodenum and create the conduit. This is then followed by a thoracic phase where the specimen is resected and anastomosis completed. Advantages include good oncologic "en bloc" lymph node dissections of the stomach and thoracic esophagus, decreased incidence of anastomotic leak, and decreased injury of the recurrent laryngeal nerve ${ }^{[27]}$. Disadvantages include contamination of the chest, which can lead to longer hospital stays, decreased quality of life if anastomotic leak occurs, and increased pulmonary morbidity secondary to the need for single-lung ventilation ${ }^{[27]}$.

Suzuki et al. ${ }^{[31]}$ best described the McKeown three-field esophagectomy using a minimally invasive approach entailing a thoracic phase similar to a minimally invasive IL approach, an abdominal phase 
Table 2. Review of short-term outcomes of minimally invasive esophagectomy vs, open esophagectomy

\begin{tabular}{lllllcc}
\hline Study & Design & Period & OE:MIE & $\begin{array}{c}\text { Respiratory } \\
\text { complications }\end{array}$ & $\begin{array}{c}\text { Surgical } \\
\text { complications }\end{array}$ & $\begin{array}{c}\text { 30 day } \\
\text { mortality }\end{array}$ \\
\hline Biere et al. ${ }^{[33]}$ Europe (2012) & RCT & $2005-2008$ & $56: 59$ & OE $>$ MIE & $=$ & $=$ \\
Seesing et al. ${ }^{[[4]}$ Netherlands (2017) & ND & $2011-2015$ & $433: 433$ & $=$ & OE $<$ MIE & $=$ \\
Mamidana et al. ${ }^{[35]}$ England (2012) & ND & $2005-2010$ & $6347: 1155$ & $=$ & OE $<$ MIE & $=$ \\
Nozaki et al. ${ }^{[66]}$ Japan (2018) & P & $2006-2013$ & $109: 101$ & OE $>$ MIE & OE $<$ MIE & $=$ \\
Takeuchi et al. ${ }^{[37]}$ Japan (2018) & ND & $2011-2012$ & $3515: 3515$ & $=$ & OE $<$ MIE & $=$ \\
\hline
\end{tabular}

MIE: minimally invasive esophagectomy; OE: open esophagectomy; RCT: randomized control trial; ND: national data; P: prospective data; =: equivalent

which also includes a dissection similar to minimally invasive IL, followed by termination after a cervical anastomosis is completed ${ }^{[27,31]}$. Advantages include excellent oncologic "en bloc" lymph node dissections of the stomach and thoracic esophagus similar to that of IL in addition to easier management of leaks given the cervical anastomosis ${ }^{[27]}$. Disadvantages include increased incidence of recurrent laryngeal nerve injury and oropharyngeal dysfunction compared to IL and increased rates of anastomotic leak ${ }^{[27]}$.

DePaula et al. ${ }^{[26]}$ best described the minimally invasive transhiatal esophagectomy, which entails starting with the abdominal phase similar to an IL, continuing the esophageal mobilization into the mediastinum, and ending with a cervical dissection, delivering the specimen through the neck and completing the anastomosis. Advantages include decreased pulmonary morbidity secondary to eliminating the thoracotomy/thoracoscopy segment and easy management of cervical leaks ${ }^{[27]}$. Disadvantages include increased dysphagia that is oropharyngeal in nature and secondary to recurrent laryngeal nerve injury and access for mediastinal lymph node dissections ${ }^{[27]}$.

Other techniques described, but not as frequently performed, include vagal-sparing esophagectomy designed to eradicate postoperative complications such as delayed gastric emptying, dumping syndrome, and post-vagotomy diarrhea. Another technique, laparoscopic inversion esophagectomy, does not include lymph node dissection of the mediastinum, and is only suitable for benign disease ${ }^{[27,28]}$. For all MIEs, anastomotic techniques have varied. Cervical anastomosis has been described using either a two-layer handsewn, circular or linear stapled anastomotic technique, with thoracic anastomosis employing the same. More recently, the OrVil (Covidien, Mansfield, MA, USA), which is a stapling device utilized trans orally, has touted benefits including the elimination of the technical assistance needed to attach the anvil to the esophagus ${ }^{[27]}$. Other technical issues include the decision of whether or not to perform a conduit emptying procedure (pyloroplasty, pyloromyotomy, or Botox injection), gastric ischemic conditioning, or prophylactic thoracic duct ligation, none of which have demonstrated a substantial difference in outcomes $^{[27]}$.

\section{Robotic esophagectomy}

Although the use of minimally invasive techniques has many advantages including lower respiratory complications and equivalent 30-day mortality [Table 2] ${ }^{[32-37]}$, the use of thoracoscopic and laparoscopic surgery also has many drawbacks. First, visualization using both techniques is limited to two dimensions. Second, with thoracoscopy, the need of the intercostal spaces to function as a fulcrum often leads to nerve injury, postoperative pain, and paresthesias ${ }^{[27]}$. As these obstacles have not been unique just to esophagectomy, many have sought to bypass these challenges resulting in the development of robotic surgery using computer-assisted surgical systems. Today, the da Vinci Surgical System (Intuitive Surgical, Sunnyvale, CA, USA $)^{[27,38]}$ is the only robotic platform that is currently Food \& Drug Administration approved and available in a commercial platform. However, more models are on the horizon.

In 2002, Melvin et al. ${ }^{[38]}$ first reported completion of a robotic esophagectomy, and, in 2003, Horgan described his experience performing the first robotic-assisted THE. Kernstine et al ${ }^{[39,40]}$ documented the first totally 
robotic McKeown three-field esophagectomy 1 year later. It included both the thoracic and abdominal phases followed by cervical anastomosis described for the MIE with differing port placements ${ }^{[39]}$. Dunn et al. ${ }^{[41]}$ were the first to describe their longer-term outcomes reporting on their 3-year experience performing THE, and others have more recently described the robotic IL esophagectomy. Today, similar to MIE, there are several additional combinations of thoracic and abdominal phases including VATS/mini-thoracotomy/ thoracotomy and laparoscopy/mini-laparotomy/handport or traditional laparotomy (also known as the hybrid robotic esophagectomy, Table 1, Items 10-13).

The use of computer-assisted technology (also known as robotics) provides several advantages including 10 -fold magnification and three-dimensional visualization ${ }^{[27,38,42]}$. The endowrist provides seven degrees of freedom and works to simulate normal wrist movements, while it employs a motion filter up to $60 \mathrm{~Hz}$ that works to reduce tremor ${ }^{[38,42]}$. Most importantly, for most uses, the fulcrum of the instrument lies inside the body instead resting on the body wall, which helps to decrease postoperative pain ${ }^{[42]}$. Although the depth of the benefits cannot be denied, there are some important disadvantages. Access to robotic platforms can be limited depending on the resources of the host institution. Given the expense attached to their use, specific departments must often be able to establish need to justify the cost, which can prove difficult for smaller centers. Surgeon comfort can be a challenging hurdle to overcome given unfamiliarity with the use of this platform in the aging surgeon population, and lack of training in new graduates. Most importantly, the lack of haptic feedback makes the use of robotic surgery challenging once it is incorporated in one's practice, which can increase the rate of devastating and life-threatening complications in novice users.

\section{Learning curve of minimally invasive and robotic esophagectomy}

As stated above, performing minimally invasive or robotic-assisted procedures is technically complex and they have significant learning curves. Decker et al. ${ }^{[43]}$ specifically reviewed the relationship between surgical experience and minimally invasive esophagectomy outcomes and found centers performing 50 or more cases had lower morbidity and mortality rates than centers with less expertise ${ }^{[27]}$. They also had more experience performing more complex lymph node dissections. Early estimates of cases needed to obtain proficiency resided around 35-40 operations, with 25 cases used as a benchmark required for competent performance of a lymphadenectomy ${ }^{[27,43]}$. Today, the precise number of procedures needed to determine if a surgeon is proficient has still not been definitely established, as Claassen et al ${ }^{[4]}$ described in their recent review. However, parameters such as estimated blood loss, operative time, the number of lymph nodes retrieved, anastomotic leak rate, duration of hospital stay, and overall complication and mortality rates can serve as benchmarks.

Regarding robotic esophagectomy, the reports have been somewhat varied and recent articles estimate the optimal number to range between 20-80 cases depending on the outcome parameter surveyed ${ }^{[45-47]}$. Park et al. ${ }^{[45]}$ retrospectively reviewed 33 patients divided into two groups, the first 20 cases and the subsequent 13 . While the operative time, robotic console time, lymph node dissections, and blood loss were similar between the two groups, the incidence of vocal cord palsy was significantly lower in Group $2^{[45]}$. Zhang et al. ${ }^{[46]}$ demonstrated that 26 cases were required to gain proficiency of robotic-assisted McKeown esophagectomy for surgeons experienced in open and thoraco-laparoscopic esophagectomy. More specifically related to the learning curve, they estimated robotic-assisted esophagus dissection would require operations on 26 patients with stomach mobilization requiring 14 operations $^{[46]}$. The bedside assistant would need at least nine cases to achieve an optimal technical level of thoracic docking, and 16 cases for abdominal docking ${ }^{[46]}$. Park et al. ${ }^{[47]}$ had a more varied range, demonstrating that the number of harvested lymph nodes increased from 25 before 30 cases to 45 after, and vocal cord palsy decreased from $36 \%$ before 60 cases to $17 \%$ after. Total operative time decreased from 496 to $431 \mathrm{~min}$, rate of anastomotic leakage decreased from $15 \%$ to $2 \%$, and the length of stay decreased from 24 to 14 days after 80 cases $^{[47]}$. Clearly, the use of robotics adds a level of complexity to the case and requires many hours of training and multiple cases for a surgeon to perfect their technique to decrease the risk to the patient. 


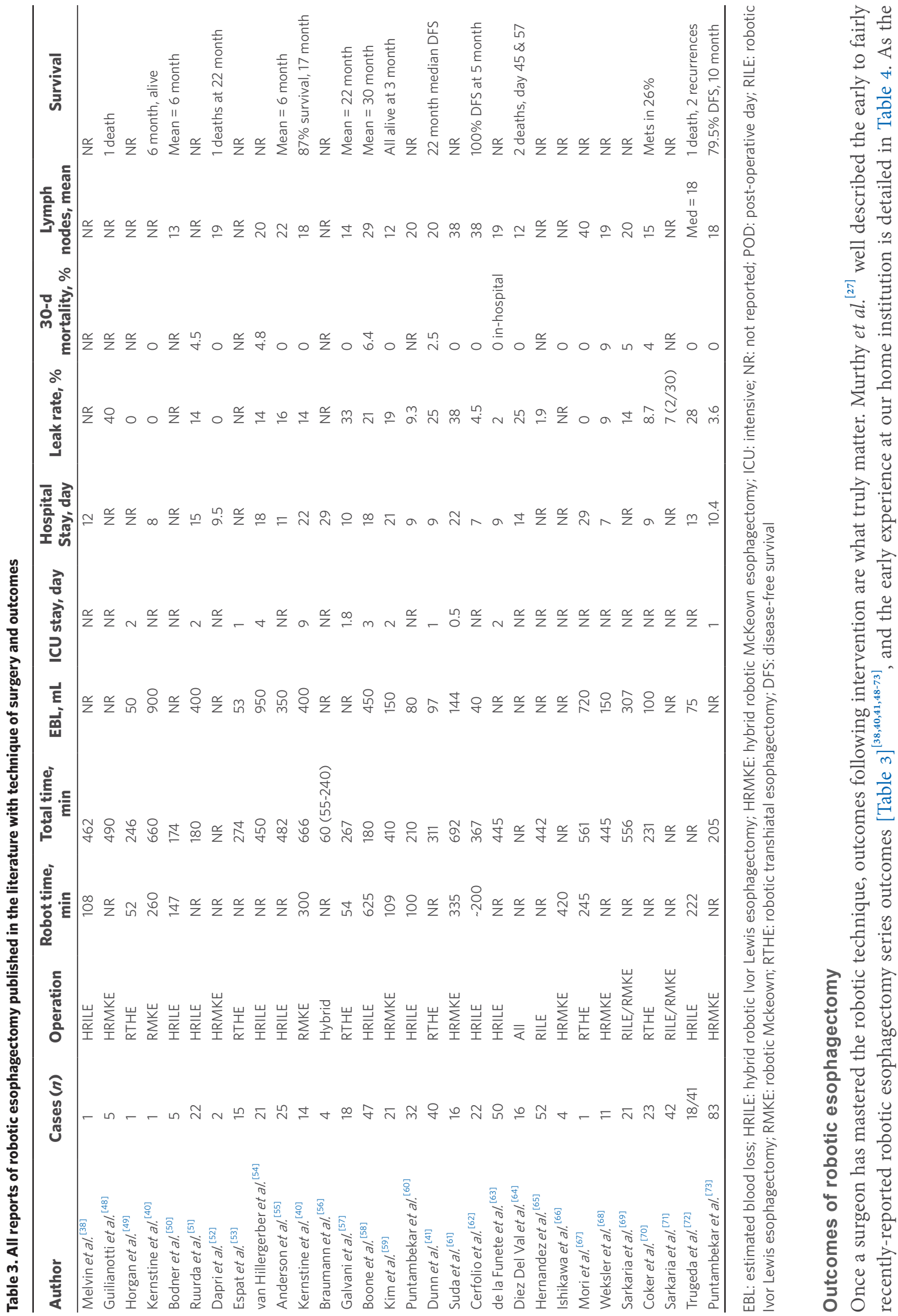


Table 4. The DHMC experience

\begin{tabular}{|c|c|}
\hline Patient demographics & Robotic esophagectomy, $n=40$ \\
\hline Age, Mean (SD) & $63.3(8.6)$ \\
\hline Male, (\%) & $36(90.0)$ \\
\hline Pack years, Mean (SD) & $46.5(38.5)$ \\
\hline \multicolumn{2}{|l|}{ Smoking status, (\%) } \\
\hline Current & $6(15.0)$ \\
\hline Former & $24(60.0)$ \\
\hline Never & $10(25.0)$ \\
\hline \multicolumn{2}{|l|}{ Alcohol status, (\%) } \\
\hline None & $9(22.5)$ \\
\hline Current use $^{1}$ & $19(47.5)$ \\
\hline Prior use ${ }^{1}$ & $2(5.0)$ \\
\hline Prior heavy use $\mathrm{e}^{2}$ & $10(25.0)$ \\
\hline Induction therapy, (\%) & $33(82.5)$ \\
\hline Operative time, mins, Mean (SD) & $512.7(70.2)$ \\
\hline Length of stay, days, Median (range) & $9(5-38)$ \\
\hline \multicolumn{2}{|l|}{ Complications $^{3},(\%)$} \\
\hline Anastomotic Leak ${ }^{4}$ & $6(15.0)$ \\
\hline Pneumonia & $4(10.0)$ \\
\hline Atrial fibrillation ${ }^{5}$ & $6(15.0)$ \\
\hline Chyle leak ${ }^{6}$ & $4(10.0)$ \\
\hline 30-day mortality, (\%) & 0 \\
\hline
\end{tabular}

${ }^{1} \leq 7$ drinks per week for females, $\leq 14$ drinks per week for males; ${ }^{2}>7$ drinks per week for females, $>14$ drinks per week for males; ${ }^{3}$ within 30 -days of index procedure; ${ }^{4}$ requiring surgical intervention; ${ }^{5}$ requiring treatment; ${ }^{6}$ requiring drainage/medical treatment only. All esophagectomies were performed using either an Ivor Lewis or McKeown approach with an EEA stapler for the anastomoses in the chest and a combined stapled/handsewn approach for the neck anastomoses, respectively. Esophageal cancer was the indication for all of the esophagectomies and all patients received neoadjuvant chemoradiation with a cisplatin doublet and $54 \mathrm{~Gy}$. The TNM staging ranged from T2NOMO to T3N2MO. The procedure time was averaged between one senior surgeon ( $\geq 10$ years of experience) and one junior surgeon ( $<2$ years of experience). Anastomotic leaks were addressed surgically by either stent placement or repair of the anastomosis for Ivor Lewis complications and washout of the neck for McKeown complications. DHMC: Dartmouth Hitchcock Medical Center; EEA: end-to-end anastomoses; TNM: Tumor, Node, Metastasis

number of studies presented is large, the number of experiences has also varied between the different types of esophagectomy. Detailing the IL experience, Cerfolio et al. ${ }^{[62]}$ originally detailed the outcomes of 22 patients who underwent robotic-assisted IL esophagectomy (also known as RAILE; note: for these cases, the abdominal phase was performed in laparoscopic fashion). A two-layer handsewn anastomosis was fashioned for 16 patients. Morbidity was minimal, 30-day mortality was $0 \%$, and they ultimately concluded that RAILE was a safe and oncologically sound procedure ${ }^{[62]}$. Since that time, many more have reported on their experience performing robotic IL esophagectomy ${ }^{[74-81]}$ and more recently, Nora et al. ${ }^{[82]}$ reviewed outcomes of RAILE. When completed by an experienced surgeon, RAILE has comparable times to esophagectomies performed via minimally invasive approaches ${ }^{[28,83]}$. RAILE demonstrated fewer complications (wound, pulmonary, cardiovascular, and overall) compared with open IL esophagectomies and duration of hospital stay was significantly lower in the RAILE versus open cohort. However, as expected, RAILE resulted in increased pulmonary complications compared to RATE ${ }^{[82]}$. Conversely, RATE demonstrated increased rates of major complications compared to RAILE including an increased risk of anastomotic leak, higher incidence of recurrent laryngeal nerve injuries, wound complications, and $\operatorname{aspiration}^{[82]}$.

Similar to RAILE, there were initially few reports of RATE experience in the literature. Dunn et al. ${ }^{[41]}$ were one of the first groups to report their outcomes in 40 patients, of which 17 had undergone neoadjuvant treatment. The operating time had a median of $311 \mathrm{~min}$ (range: 226-491 $\mathrm{min}$ ), and the conversion rate was $12.5 \%{ }^{[41]}$. The morbidity rate of their cohort was high, and complications included pneumonia (20\%), pleural effusion (45\%), anastomotic leak (25\%), recurrent laryngeal nerve injury (35\%), and anastomotic stricture 
$(67.5 \%)^{[27,41]}$. Regarding lymph node dissection, the mean \pm SD was $18.5 \pm 8.7$, and the 30 -day mortality was $2.5 \%$. Interestingly, the authors reported using biologic mesh to reinforce the hiatus to address the issue of postoperative diaphragmatic hernias, a step rarely performed today ${ }^{[27,41]}$. Others have also reported similar outcomes ${ }^{[84-87]}$. More recently, Wecowski et al. ${ }^{[88]}$ prospectively reported their experience in incorporating a robotic platform for transhiatal esophagectomy. Operative duration was 334 (364 \pm 108.8$) \mathrm{min}$, and length of stay was 8 days. Morbidity rates were also fairly high and included respiratory failure requiring intubation $(20 \%)$, pneumonia (4\%), surgical site infection (11\%), renal insufficiency $(2 \%)$, and UTI $(2 \%)^{[88]}$. One patient died within 30 days secondary to cardiac arrest. The conversion rate was $9 \%$, however none were converted in the last 25 operations and blood loss also decreased over time from an initial average of $200 \mathrm{cc}^{[88]}$.

Kernstine et al. ${ }^{[89]}$ were the first to describe their completely robotic McKeown esophagectomy and three-field lymphadenectomy experience. Their series included 14 patients, of whom eight underwent a completely robotic operation ${ }^{[27,89]}$. The anastomotic leak rate was $7 \%$, stricture rate $14 \%$, and average blood loss was $275 \mathrm{~mL}$. Notably, the mean operating duration was $11.1(660 \mathrm{~min}) \pm 1.1 \mathrm{~h}^{[27,89]}$. More recently, Sarkaria et al. ${ }^{[60]}$ described total robotic esophagectomy experience in 2012. In their cohort of 21 patients, 4 underwent McKeown esophagectomy and 17 underwent RAILE. The median operating time was 556 min and the conversion rate to an open procedure was $24 \%$. The average blood loss was $307 \mathrm{~mL}$ while the mortality rate was $5 \%$. The anastomotic leak rate was clinically significant at $14 \%$, and two patients developed a gastrobronchial fistula secondary to a leak ${ }^{[69]}$. Others have more recently reported their outcomes and use of various techniques with similar results ${ }^{[71,90,91]}$.

\section{Outcome comparisons of open, minimally invasive and robotic-assisted esophagectomy}

Although review of independent outcomes in robotic surgery is important, comparing open esophagectomy to minimally invasive approaches will help determine equality and/or superiority to current techniques. In looking at open versus minimally invasive procedures, Naffouje et al. ${ }^{[92]}$ reported their results following a propensity score-matched analysis using the NSQIP database evaluating participants who underwent OE or MIE. One hundred sixty-one OTTE patients were matched with patients 1:1 who underwent minimally invasive transthoracic esophagectomy. Higher completion rates of abdominal and mediastinal lymph node dissections were appreciated in the OTTE subgroup $(26.7 \%$ vs. $3.1 \%$ and $38.5 \%$ vs. $16.1 \%$, respectively; $P<0.001$ ), and the mean operative times were also shorter (329 $\min v s .414 \mathrm{~min} ; P<0.001)^{[92]}$. Conversely, higher rates of wound complications were appreciated in the OTTE population (7.5\% vs. $1.9 \%)$, the median hospitalization was longer (10 days vs. 8 days), more patients required discharge to a facility $(18.0 \% v s$. $8.1 \%)$, and the need for postoperative blood transfusion trended towards significance $(13.0 \% \mathrm{vs.} 6.8 \%$; $P=0.092)$. They concluded the OTTE cohort demonstrated higher complication rates $(46.0 \%$ vs. $33.5 \%$; $P=0.028$ ); however, there was no difference in the rates of negative margins, anastomotic leak, need for reoperation, readmission, or mortality ${ }^{[92]}$. The results were uniformly comparable when they evaluated laparoscopic $v s$. robotic approaches, with the exception of higher rates of procured lymph nodes when completed laparoscopically and higher rates of mediastinal lymph node procurement when using the robotic approach $^{[92]}$.

Zhang et al ${ }^{[93]}$ most recently compared minimally invasive to robotic esophagectomy. They included 66 matched pairs also using propensity score-matched cohorts, finding operative time in the RAILE group to be significantly longer than that in the thoracoscopic-assisted Ivor Lewis (TAIL) group (302.0 \pm 62.9 min vs. $274.7 \pm 38.0 \mathrm{~min}, P=0.004)^{[93]}$. There was no significant difference in the rates of overall complications (28.8\% vs. $24.2 \%, P=0.554)$, blood loss $\{200.0 \mathrm{~mL}$ [interquartile range (IQR) 100.0-262.5 mL] vs. $200.0 \mathrm{~mL}$ (IQR 150.0-245.0 mL), $P=0.100\}$, length of stay [9.0 days (IQR 8.0-12.3 days) vs. 9.0 days (IQR 8.011.3 days $), P=0.517$ ], and total number of dissected lymph nodes $(19.2 \pm 9.2$ vs. $19.3 \pm 9.5, P=0.955)$. There were two conversions in the RAILE group, and there were no 30 -day readmissions. 
Chao et al. ${ }^{[94]}$ also performed a propensity-matched analysis evaluating lymph node procurement in robotic and minimally invasive procedures, reporting no conversion to open thoracotomy in either group and similar rates of intraoperative blood loss and the need for blood transfusions ${ }^{[94]}$. The mean number of dissected nodes was similar in the two study groups, except for the area of the left recurrent laryngeal nerve. Notably, there was no significant difference between the RAILE and TAIL groups in regard to rates of recurrent laryngeal nerve palsy $(20.6 \% v$ s. $29.4 \%$, respectively, $P=0.401)$ and pulmonary complications $(5.9 \% \text { vs. } 17.6 \% \text {, respectively, } P=0.259)^{[94]}$.

Regarding direct comparison of open to robotic esophagectomy, van der Sluis et al. ${ }^{[95,96]}$ conducted a randomized controlled trial evaluating the robot-assisted minimally invasive thoraco-laparoscopic esophagectomy versus open transthoracic esophagectomy for resectable esophageal cancer (ROBOT trial) in an attempt to answer this question. Notably, this study represents the only report evaluating long-term, 5-year robotic-assisted esophagectomy outcomes. This was an investigator-initiated and investigator-driven single-center randomized controlled parallel-group, superiority trial including all adult patients (age $\geq 18$ and $\leq 80$ years) with histologically proven, surgically resectable (cT1-4a, No-3, Mo) esophageal carcinoma of the intrathoracic esophagus who demonstrated a performance status in line with the European Clinical Oncology Group scoring of 0,1 or $2^{[95]}$. The percentage of overall complications (Grade 2 and higher) according to the modified Clavien-Dindo classification was the primary outcome. It started in January 2012 and patients were followed for 5 years. In total, 112 patients diagnosed with surgically resectable esophageal cancer were randomly assigned to either RAMIE or OTTE. Occurrence of surgery-related postoperative complications was the primary endpoint (designated using the modified Clavien-Dindo classification, Grades 2-5).

The RAMIE (59\%) population experienced fewer surgery-related postoperative complications compared to the OTTE (80\%) population (RR with RAMIE 0.74; 95\%CI, 0.57-0.96; $P=0.02$ ), less median blood loss (400 mL vs. $568 \mathrm{~mL}, P<0.001$ ), fewer pulmonary (RR 0.54; 95\%CI, $0.34-0.85 ; P=0.005)$ and cardiac complications (RR $0.47 ; 95 \% \mathrm{CI}, 0.27-0.83 ; P=0.006$ ), and less postoperative pain (mean visual analog scale, 1.86 vs. 2.62; $P<0.001$ ) compared to OTTE ${ }^{[96]}$. Regarding quality of life, by POD 14 , participants reported better functional recovery in the RAMIE population (RR $1.48,95 \% \mathrm{CI}: 1.03-2.13 ; P=0.038$ ) and the quality of life (QOL) score was better at discharge [mean difference QOL score 13.4 (2.0-24.7, $P=0.02)$ ] and 6 weeks thereafter [mean difference 11.1 QOL score $(1.0-21.1 ; P=0.03)]$. Most importantly, comparable oncologic outcomes were appreciated in both the short- and long-term periods at a medium follow-up (40 months) ${ }^{[96]}$.

Finally, it is important to mention the cost variations among the open, minimally invasive, and robotic techniques. Proponents of minimally invasive and robotic techniques have stated that, although they incur a higher surgical expense, this is often counterbalanced by the savings accrued through an accelerated recovery both in hospital and at home. Conversely, critics suggest that the added cost of MIE and robotic procedures is often not recovered in the postoperative period, despite the decreased or lack of ICU stay. The review of the literature supports both sides of the argument. Lee et al. ${ }^{[97]}$ utilized a decision-analysis model to compare the estimated costs of MIE to OE and found that, over a 1-year time period, MIE cost less than $\mathrm{OE}$, with the differences mostly attributed to variations in length of stay. Others found similar findings of lower overall cost at different time points, which were also attributed to decreased postoperative costs ${ }^{[98,99]}$. Conversely, Liu et al. ${ }^{[100]}$ compared MIE to OE and found that, even though the postoperative costs of MIE were significantly lower, this did not offset the higher procedural expense, as was found by other authors performing similar analyses ${ }^{[101-103]}$.

Unfortunately, there is a paucity of data comparing the cost-effectiveness of either open to robotic esophagectomies or minimally invasive to robotic esophagectomies. Ultimately, more cost studies evaluating robotic versus open and minimally invasive approaches is needed to validate the cost- 
effectiveness of these techniques. More importantly, as Klapper et al. ${ }^{[104]}$ stated, "the onus is on our field to establish the clear cost advantages of robotic applications if we desire formal acceptance and integration into our practices".

\section{Discussion}

Surgical treatment of esophageal cancer has evolved from an open procedure involving thoracotomy and laparotomy to minimally invasive hybrid techniques, to completely minimally invasive and/or roboticassisted/totally robotic procedures. While the advantages of minimally invasive procedures and the needed learning curve for implementation of minimally invasive esophageal resection techniques is still not completely clear, robotic-assisted esophagectomies have consistently demonstrated lower rates of overall complications, better scores in factors related to patient satisfaction, and have produced sound oncologic outcomes. Specifically, robotic techniques result in less surgery-related and cardiopulmonary complications overall, lower postoperative pain which appeared to improve short-term quality of life, and a better shortterm recovery from a functional standpoint in the postoperative period compared to OTTE ${ }^{[96]}$. Oncological outcomes are also comparable and in line with current standards ${ }^{[96]}$. Until the ROBOT trial, no study had specifically surveyed long term, 5-year outcomes or quality of life metrics. This information will hopefully enable more programs to consider implementation of robotic surgery for esophageal cancer operations in the future.

Nevertheless, the expense of the robotic platform and surgeon experience limit their utility in some hospital settings. Interestingly, while some have touted the needed learning curve of robotic surgery to be prohibitive to its incorporation in surgical practice (described as the longer initial operating times that eventually decrease with experience), van der Sluis et al. ${ }^{[95,96]}$ reported a much steeper learning curve for the robotic approach compared to the traditional MIE (e.g., laparoscopic or thoracoscopic approaches), which significantly reduces the number of surgeries needed to plateau, and may be of interest to smaller robotic centers. Most experts agree that the proctor's experience with robotic surgery and the learning surgeon's willingness to practice simulation are the most important in working to reduce the time to robotic competency.

There are several limitations for this review. First, with the exception of high-volume centers, esophagectomy in general is a procedure that is performed somewhat rarely overall. Given this, the cohorts used for comparison are often quite small. Specifically, when comparing institutional experience of MIE vs. robotic procedures, MIE has a breadth including 1000s of cases with excellent outcomes compared to the best robotic experiences, which only include 100s of cases. While MIE has certainly been tested in regards to oncologic outcomes, and lower morbidity, robotic surgery still needs to duplicate such volumes at experienced institutions to demonstrate durability. Second, there is significant breadth in the types of esophagectomy that one can perform depending on a surgeon's experience with open, laparoscopic, thoracoscopic, and robotic techniques. Furthermore, even if the same procedure is performed, there are often variations in each individual step that make comparison difficult (the use of pyloric procedures, amount of Kocher mobilization employed, use of jejunostomy tubes, etc.). The perioperative pathways can also significantly differ in the pre-, peri-, and postoperative setting, leading to even more variance and decrease the ability to compare different groups. There are procedural guides that can help to limit this perioperative variation, which we recommend for all surgeons, especially those just entering practice or learning new robotic techniques. Third, IL esophagectomy is the most commonly performed esophageal cancer procedure, hence most outcome metrics are based on study of this procedure type alone. While there are some data on transhiatal and McKeown techniques, this is less abundant and is often limited to small cohorts or single institution studies. Fourth, mention of the specific robotic platform used in the reporting of operating times for the robotic studies has been mostly absent. Inclusion of this detail in future reports will help surgeons understand the relatability of these results to their specific practice. Last, the 
measurement of quality of life metrics has been absent from almost all studies with one exception ${ }^{[105]}$, the ROBOT trial. Ultimately, this information including complication rates and oncologic outcomes can help patients make educated decisions.

\section{Future innovations}

Clearly there is a trend towards decreasing the invasiveness of esophageal resections. As surgeons' minimally invasive skills improve, it is clear that surgical choices will steer away from hybrid procedures to either completely minimally invasive or fully robotic techniques. Additionally, technology will allow for surgeons to improve upon the most difficult portions of the procedure, advancing the overall flow of the operation. For example, the mediastinal lymph node dissection is often suboptimal in transhiatal esophagectomies given lack of direct visualization in the upper mediastinum. The need for a cervical incision in transhiatal and McKeown esophagectomies can be morbid and increasingly prone to surgical site infections given that the rest of the procedure can be performed with minimally invasive or robotic fashion. In Japan, use of non-thoracic radical esophagectomy via the transcervical and transhiatal approaches with mediastinoscopic devices has attempted to address these problems resulting in feasible surgical outcomes ${ }^{[106-109]}$. This technique has been found to be especially helpful with squamous cell carcinoma of the esophagus, the most common histology of esophageal cancer in Japan and Asia, and often involving extensive mediastinal spread that can occur at an early age ${ }^{[107]}$. Additionally, esophagectomy with mediastinal lymph node dissection, including the area along the recurrent laryngeal nerves, has become the gold standard for radical surgical resection, however the view achieved with standard cervical incisions has been limited ${ }^{[107]}$. The introduction of other novel minimally invasive techniques for the lymph node dissection, such as the use of single port or robotic surgical devices, has expanded the options available to achieve improved dissection and, ultimately, better oncologic outcomes ${ }^{[107]}$. There is no doubt that surgeons will continue to optimize all parts of the esophagectomy operation to maximally streamline aspects of the case in a minimally invasive fashion.

\section{CONCLUSION}

Today, surgical treatment strategies involving the use of open, thoracoscopic, laparoscopic, and robotic techniques are routinely used to resect and reconstruct the esophagus ${ }^{[27]}$. However, the need to decrease the morbidity and mortality of open and hybrid surgical treatment for esophageal cancer has driven the trend towards completely minimally invasive techniques for resection, and, more recently, robotic assistance to perform esophagectomy. Robotic-assisted esophagectomy represents the newest innovation in MIE with its own unique benefits and challenges; notably, the need for specific teaching programs and proctored learning, both of which are mandatory. However, as more studies are completed which confirm the lower incidence of major complications, and similar overall and disease-free survival compared to open approaches, the use of robotic techniques to perform esophagectomy will likely become more common and work alongside other proven techniques to deliver efficient oncologic care in the least invasive fashion.

\section{DECLARATIONS}

\section{Authors' contributions}

Made substantial contributions to conception and design of the study and performed data analysis and interpretation: Hasson RM, Fay KA, Phillips JD, Millington TM, Finley DJ

Performed data acquisition, as well as provided administrative, technical, and material support: Hasson RM, Fay KA, Phillips JD

\section{Availability of data and materials}

Not applicable. 


\section{Financial support and sponsorship}

None.

\section{Conflicts of interest}

J Phillips has previously received consulting fees from Intuitive Surgical Inc. but has no ongoing relationship. All author authors report no conflicts of interest to disclose related to this work.

\section{Ethical approval and consent to participate}

Not applicable.

\section{Consent for publication}

Not applicable.

\section{Copyright}

(C) The Author(s) 2020.

\section{REFERENCES}

1. Malhotra GK, Yanala U, Ravipati A, Follet M, Vijayakumar M, et al. Global trends in esophageal cancer. J Surg Oncol 2017;115:564-79.

2. Mariette C, Markar SR, Dabakuyo-Yonli TS, Meunier B, Pezet D. Hybrid minimally invasive esophagectomy for esophageal cancer. N Engl J Med 2019;380:152-62.

3. American Cancer Society. Key Statistics for Lung Cancer. Available from: https://www.cancer.org/cancer/non-small-cell-lung-cancer/ about/key-statistics.html [Last accessed on 13 May 2020]

4. Enzinger PC, Mayer RJ. Esophageal cancer. N Engl J Med 2003;349:2241-52.

5. Giugliano DN, Berger AC, Rosato EL, Palazzo F. Total minimally invasive esophagectomy for esophageal cancer: approaches and outcomes. Langenbecks Arch Surg 2016;401:747-56.

6. Sabra MJ, Smotherman C, Kraemer DF, Nussbaum MS, Tepas JJ Rd, et al. The effects of neoadjuvant therapy on morbidity and mortality of esophagectomy for esophageal cancer: American college of surgeons national surgical quality improvement program (ACS-NSQIP) 2005-2012. J Surg Oncol 2017;115:296-300.

7. Taurchini M, Cuttitta A. Minimally invasive and robotic esophagectomy: state of the art. J Vis Surg 2017;3:125.

8. Schumer E, Perry K, Melvin WS. Minimally invasive esophagectomy for esophageal cancer: evolution and review. Surg Laparosc Endosc Percutan Tech 2012;22:383-6.

9. Tagkalos E, Goense L, Hoppe-Lotichius M, Ruurda JP, Babic B, et al. Robot-assisted minimally invasive esophagectomy (RAMIE) compared to conventional minimally invasive esophagectomy (MIE) for esophageal cancer: a propensity-matched analysis. Dis Esophagus 2020;33:doz060.

10. Torek F. The causes of failure in the operative treatment of carcinoma of the esophagus. Ann Surg 1929;90:496-506.

11. Kauppila JH, Xie S, Johar A, Markar SR, Lagergren P. Meta-analysis of health-related quality of life after minimally invasive versus open oesophagectomy for oesophageal cancer. Br J Surg 2017;104:1131-40.

12. Glatz T, Marjanovic G, Kulemann B, Sick O, Hopt UT, et al. Hybrid minimally invasive esophagectomy vs. open esophagectomy: a matched case analysis in 120 patients. Langenbecks Arch Surg 2017;402:323-31.

13. Torek F. The operative treatment of carcinoma of the esophagus. Ann Surg 1915;61:385-405.

14. Karamanou M, Markatos K, Papaioannou TG, Zografos G, Androutsos G. Hallmarks in history of esophageal carcinoma. J BUON. 2017;22:1088-1091.

15. Lewis I. The surgical treatment of carcinoma of the oesophagus; with special reference to a new operation for growths of the middle third. Br J Surg 1946;34:18-31.

16. McKeown KC. Total three-stage oesophagectomy for cancer of the oesophagus. Br J Surg 1976;63:259-62.

17. Orringer MB, Sloan H. Esophagectomy without thoracotomy. J Thorac Cardiovasc Surg 1978;76:643-54.

18. Rindani R, Martin CJ, Cox MR. Transhiatal versus Ivor-Lewis oesophagectomy: is there a difference? Aust N Z J Surg 1999;69:187-94.

19. Homesh NA, Alsabahi AA, Al-Agmar MH, Alwashaly AA, Valenzuela RE. Transhiatal versus transthoracic resection for oesophageal carcinoma in Yemen. Singapore Med J 2006;47:54-9.

20. Shichinohe T, Hirano S, Kondo S. Video-assisted esophagectomy for esophageal cancer. Surg Today 2008;38:206-13.

21. Booka E, Takeuchi H, Kikuchi H, Hiramatsu Y, Kamiya K. Recent advances in thoracoscopic esophagectomy for esophageal cancer. Asian J Endosc Surg 2019;12:19-29.

22. Dallemagne B, Weerts JM, Jehaes C, Markiewicz S, Lombard R. Laparoscopic Nissen fundoplication: preliminary report. Surg Laparosc Endosc 1991;1:138-43.

23. Cuschieri A, Shimi S, Banting S. Endoscopic oesophagectomy through a right thoracoscopic approach. J R Coll Surg Edinb 1992;37:7-11.

24. Cuschieri A. Endoscopic subtotal oesophagectomy for cancer using the right thoracoscopic approach. Surg Oncol 1993;2:3-11. 
25. Collard JM, Lengele B, Otte JB, Kestens PJ. En bloc and standard esophagectomies by thoracoscopy. Ann Thorac Surg 1993;56:675-9.

26. DePaula AL, Hashiba K, Ferreira EA, de Paula RA, Grecco E. Laparoscopic transhiatal esophagectomy with esophagogastroplasty. Surg Laparosc Endosc 1995;5:1-5.

27. Murthy RA, Clarke NS, Kernstine KH Sr. Minimally invasive and robotic esophagectomy: a review. Innovations (Phila) 2018;13:391403.

28. Levy RM, Trivedi D, Luketich JD. Minimally invasive esophagectomy. Surg Clin North Am 2012;92:1265-85.

29. Levy RM, Pennathur A, Luketich JD. Randomized trial comparing minimally invasive esophagectomy and open esophagectomy: early perioperative outcomes appear improved with a minimally invasive approach. Semin Thorac Cardiovasc Surg 2012;24:153-4.

30. Luketich JD, Pennathur A, Awais O, Levy RM, Keeley S, et al. Outcomes after minimally invasive esophagectomy: review of over 1000 patients. Ann Surg 2012;256:95-103.

31. Suzuki Y, Urashima M, Ishibashi Y, Abo M, Omura N, et al. Hand-assisted laparoscopic and thoracoscopic surgery (HALTS) in radical esophagectomy with three-field lymphadenectomy for thoracic esophageal cancer. Eur J Surg Oncol 2005;31:1166-74.

32. Oshikiri T, Takiguchi G, Miura S, Takase N, Hasegawa H, et al. Current status of minimally invasive esophagectomy for esophageal cancer: Is it truly less invasive?. Ann Gastroenterol Surg 2018;3:138-45.

33. Biere SS, van Berge Henegouwen MI, Maas KW, Bonavina L, Rosman C, et al. Minimally invasive versus open oesophagectomy for patients with oesophageal cancer: a multicentre, open-label, randomised controlled trial. Lancet 2012;379:1887-92.

34. Seesing MFJ, Gisbertz SS, Goense L, van Hillegersberg R, Kroon HM, et al. A Propensity Score Matched Analysis of Open Versus Minimally Invasive Transthoracic Esophagectomy in the Netherlands. Ann Surg 2017;266:839-46.

35. Mamidana R, Bottle A, Aylin P, Faiz O, Hanna GB. Short-term outcomes following open versus minimally invasive esophagectomy for cancer in England: a population-based national study. Ann Surg 2012;255:197-203.

36. Nozaki I, Kato K, Igaki H, Ito Y, Daiko H, et al. Evaluation of safety profile of thoracoscopic esophagectomy for T1bN0M0 cancer using data from JCOG0502: a prospective multicenter study. Surg Endosc 2015;29:3519-26.

37. Takeuchi H, Miyata H, Ozawa S, Udagawa H, Osugi H, et al. Comparison of Short-Term Outcomes Between Open and Minimally Invasive Esophagectomy for Esophageal Cancer Using a Nationwide Database in Japan. Ann Surg Oncol 2017;24:1821-27.

38. Melvin WS, Needleman BJ, Krause KR, Schneider C, Wolf RK, et al. Computer-enhanced robotic telesurgery. Initial experience in foregut surgery. Surg Endosc 2002;16:1790-2.

39. Kernstine KH, DeArmond DT, Karimi M, Van Natta TL, Campos JH, et al. The robotic, 2-stage, 3-field esophagolymphadenectomy. J Thorac Cardiovasc Surg 2004;127:1847-9.

40. Kernstine KH, DeArmond DT, Shamoun DM, Campos JH. The first series of completely robotic esophagectomies with three-field lymphadenectomy: initial experience. Surg Endosc 2007;21:2285-92.

41. Dunn DH, Johnson EM, Morphew JA, Dilworth HP, Krueger JL, et al. Robotic-assisted transhiatal esophagectomy: a 3-year single center experience. Dis esophagus 2013;26:159-66.

42. Gerhardus D. Robotic -assisted surgery: the future is here. J Healthc Manag 2003;48:242-51.

43. Decker G, Coosemans W, De Leyn P, Decaluwé H, Nafteux P, et al. Minimally invasive esophagectomy for cancer. Eur J Cardiothorac Surg 2009;35:13-20; discussion 20-1.

44. Claassen L, van Workum F, Rosman C. Learning curve and postoperative outcomes of minimally invasive esophagectomy. J Thorac Dis 2019;11:S777-85.

45. Park SY, Kim DJ, Kang DR, Haam SJ. Learning curve for robotic esophagectomy and dissection of bilateral recurrent laryngeal nerve nodes for esophageal cancer. Dis Esophagus 2017;30:1-9.

46. Zhang H, Chen L, Wang Z, Zheng Y, Geng Y. The learning curve for robotic McKeown Esophagectomy in Patients with esophageal cancer. Ann Thorac Surg 2018;105:1024-30.

47. Park s, Hyun K, Lee HJ, Park IK, Kim YT, et al. A study of the learning curve for robotic oesophagecotmy for oesophageal cancer. Eur J Cardiothorac Surg 2018;53:862-70.

48. Giulianotti PC, Coratti A, Angelini M, Sbrana F, Cecconi S, et al. Robotics in general surgery: personal experience in a large community hospital. Arch Surg 2003;138:777-84.

49. Horgan S, Berger RA, Elli EF, Espat NJ. Robotic-assisted minimally invasive transhiatal esophagectomy. Am Surg 2003;69:624-6.

50. Bodner JC, Zitt M, Ott H, Wetscher GJ, Wykypiel H, et al. Robotic-assisted thoracoscopic surgery (RATS) for benign and malignant esophageal tumors. Ann Thorac Surg 2005;80:1202-6.

51. Ruurda JP, Draaisma WA, van Hillegersberg R, Borel Rinkes IHM, Gooszen HG, et al. Robot-assisted endoscopic surgery: a four-year single-center experience. Dig Surg 2005;22:313-20.

52. Dapri G, Himpens J, Cadiere GB. Robot-assisted thoracoscopic esophagectomy with the patient in the prone position. J Laparoendosc Adv Surg Tech A 2006;16:278-85.

53. Espat NJ, Jacobsen G, Horgan S, Donahue P. Minimally invasive treatment of esophageal cancer: laparoscopic staging to robotic esophagectomy. Cancer J 2005;11:10-7.

54. van Hillegersberg R, Boone J, Draaisma WA, Broeders IA, Giezeman MJ, et al. First experience with robot-assisted thoracoscopic esophagolymphadenectomy for esophageal cancer. Surg Endosc 2006;20:1435-9.

55. Anderson C, Hellan M, Kernstine K, Ellenhorn J, Lai L, et al. Robotic surgery for gastrointestinal malignancies. Int J Med Robot Comput Assist Surg 2007;3:297-300.

56. Braumann C, Jacobi CA, Menenakos C, Ismail M, Rueckert JC, et al. Robotic-assisted laparoscopic and thoracoscopic surgery with the da Vinci system: a 4-year experience in a single institution. Surg Laparosc Endosc Percutan Tech 2008;18:260-6. 
57. Galvani CA, Gorodner MV, Moser F. Robotically assisted laparoscopic transhiatal esophagectomy. Surg Endosc 2008;22:188-95.

58. Boone J, Schipper ME, Moojen WA, Borel Rinkes IHM, Cromheecke GJ, et al. Robot-assisted thoracoscopic oesophagectomy for cancer. Br J Surg 2009;96:878-86.

59. Kim DJ, Hyung WJ, Lee CY, Lee JG, Haam SJ, et al. Thoracoscopic esophagectomy for esophageal cancer: feasibility and safety of robotic assistance in the prone position. J Thorac Cardiovasc Surg 2010;139:53-9.

60. Puntambekar SP, Rayate N, Joshi S, Agarwal G. Robotic transthoracic esophagectomy in the prone position: experience with 32 patients with esophageal cancer. J Thorac Cardiovasc Surg 2011;142:1283-4.

61. Suda K, Ishida Y, Kawamura Y, Inaba K, Kanaya S, et al. Robot-assisted thoracoscopic lymphadenectomy along the left recurrent laryngeal nerve for esophageal squamous cell carcinoma in the prone position: technical report and short-term outcomes. World J Surg 2012;36:1608-16.

62. Cerfolio RJ, Bryant S, Hawn MT. Technical aspects and early results of robotic esophagectomy with chest anastomosis. J Thorac Cardiovasc Surg 2013;145:90-6.

63. de la Fuente SG, Weber J, Hoffe SE, Shridhar R, Karl R, et al. Initial experience from a large referral center with robotic-assisted Ivor Lewis esophagogastrectomy for oncologic purposes. Surg Endosc 2013;27:3339-47.

64. Diez Del Val I, Loureiro Gonzalez C, Larburu Etxaniz S, Barrenetxea Asua J, Leturio Fernandez S, et al. Contribution of robotics to minimally invasive esophagectomy. J Robot Surg 2013;7:325-32.

65. Hernandez JM, Dimou F, Weber J, Khaldoun A, Hoffe S, et al. Defining the learning curve for robotic-assisted esophagogastrectomy. J Gastrointest Surg 2013;17:1346-51.

66. Ishikawa N, Kawaguchi M, Inaki N, Moriyama H, Shimada M, et al. Robot-assisted thoracoscopic hybrid esophagectomy in the semiprone position under pneumothorax. Artif Organs 2013;37:576-80.

67. Mori K, Yamagata Y, Wada I, Shimizu N, Nomura S, et al. Robotic-assisted totally transhiatal lymphadenectomy in the middle mediastinum for esophageal cancer. J Robot Surg 2013;7:385-7.

68. Weksler B, Sharma P, Moudgill N, Chojnacki KA, Rosato EL. Robot-assisted minimally invasive esophagectomy is equivalent to thoracoscopic minimally invasive esophagectomy. Dis Esophagus 2012;25:403-9.

69. Sarkaria IS, Rizk NP, Finley DJ, Bains MS, Adusumilli PS, et al. Combined thoracoscopic and laparoscopic robotic-assisted minimally invasive robotic esophagectomy using a 4-arm platform: experience, technique and cautions during early procedure development. Eu J Cardiothorac Surg 2013;43:107-15.

70. Coker AM, Barajas-Gamboa JS, Cheverie J, Jacobsen GR, Sandler BJ, et al . Outcomes of robotic-assisted transhiatal esophagectomy for esophageal cancer after neoadjuvant chemoradiation. J Laparoendosc Adv Surg Tech A 2014;24:89-94.

71. Sarkaria IS, Bains MS, Finley DJ, Adusmumilli PS, Huang J, et al. Intraoperative near-infrared fluorescence imaging as an adjunct to robotic-assisted minimally invasive esophagectomy. Innovations (Phila) 2014;9:391-3.

72. Trugeda S, Fernandez-Diaz MJ, Rodriguez-Sanjuan JC, Palazuelos CM, Fernandez-Escalante C, et al. Initial results of robot-assisted Ivor-Lewis oesophagectomy with intrathoracic hand-sewn anastomosis in the prone position. Int J Med Robot 2014;10:397-403.

73. Puntambekar S, Kenawadekar R, Kumar S, Joshi S, Argawal G, et al. Robotic transthoracic esophagectomy. BMC Surg 2015;15:47.

74. Cerfolio RJ, Wei B, Hawn MT, Minnich DJ. Robotic esophagectomy for cancer: early results and lessons learned. Semin Thorac Cardiovasc Surg 2016;28:160-9.

75. Peng JS, Nurkin SJ, Hochwald SN, Kukar M. Technique for robotic ivor lewis esophagectomy with 6-cm linear stapled side-to-side anastomosis. Ann Surg Oncol 2020;27:824.

76. Plat VD, Stam WT, Schoonmade LJ, Heineman DJ, van der Peet DL, et al. Implementation of robot-assisted Ivor Lewis procedure: robotic hand-sewn, linear or circular technique? Am J Surg 2019;S0002-9610(19)31545-4.

77. Zhang H, Wang Z, Zheng Y, Geng Y, Wang F, et al. Robotic side-to-side and end-to-side stapled esophagogastric anastomosis of Ivor Lewis esophagectomy for cancer. World J Surg. 2019;43:3074-82.

78. Wang Z, Zhang H, Wang F, Wang Y. Robotic-assisted esophagogastric reconstruction in minimally invasive Ivor Lewis esophagectomy. J THorac Dis 2019;11:1860-66.

79. Grimminger PP, Hadzijusufovic E, Babic B, van der Sluis PC, Lang H. Innovative fully robotic 4-arm Ivor Lewis esophagectomy for esophageal cancer (RAMIE4). Dis Esophagus 2020;33:doz015.

80. Wang WP, Chen LQ, Zhang HL, Yang YS, He SL, et al. Modified Intrathoracic Esophaphagogastrostomy with minimally invasive robotassisted Ivor-Lewis esophagectomy for cancer. Dig Surg 2019;36:218-25.

81. Zhang Y, Xiang J, Han Y, Huang M, Hang J, et al. Initial experience of robot-assisted Ivor Lewis esophagectomy: 61 consecutive cases from a single Chinese institution. Dis Esophagus 2018;31.

82. Nora I, Shridhar R, Meredith K. Robotic-assisted Ivor Lewis esophagectomy: technique and early outcomes. Robot Surg 2017;4:93-100.

83. Meredith K, Huston J, Andacoglu O, Shridhar R. Safety and feasibility of robotic-assisted Ivor Lewis esophagectomy. Dis Esophagus $2018 ; 31$.

84. Horst VD, Patel HD, Hewlett SC. Robotic transhiatal esophagectomy in a community hospital: evolution of technique. Am Surg 2016;82:730-2.

85. Gockel I, Lorenz D. Oncologic esophageal resection and reconstruction: open, hybrid, minimally invasive or robotic? Chirurg 2017;88:496-502.

86. Washington K, Watkins JR, Jay J, Jeyarajah DR. Oncologic resection in laparoscopic versus robotic transhiatal esophagectomy. JSLS 2019;23:e2019.00017.

87. DeLong JC, Keely KJ, Jacobsen GR, Sandler BJ, Horgan S, et al. The benefits and limitations of robotic assisted transhiatal 
esophagectomy for esophageal cancer. J Vis Surg 2016;2:156.

88. Wecowski J, Ross SB, Jadick MF, Justice A, Sucandi I, et al. The big deal: an institution's experience with robotic transhiatal esophagectomy. Am Surg 2019;85:1061-65.

89. Kernstine KH, DeArmond DT, Sahmoun DM, Campos JH. The first series of completely robotic esopahgectomies with three-filed lymphadenectomy: initial experience. Surg Endosc 2007;21:2285-92.

90. Patel S, Petrov R, Abbas A, Bakhos C. Robotic-assisted McKeown esophagectomy. J Vis Surg 2019;5:43.

91. Egberts JH, Schlemminger M, Hauser C, Becker T. Robotic-assisted McKeown procedure via a cervical mediastinoscopy avoiding an abdominal and thoracic incision. Thorac Cardiovasc Surg 2019;67:610-14.

92. Naffouje SA, Salloum RH, Khalaf Z, Salti G. Outcomes of open versus minimally invasive Ivor Lewis esophagectomy for cancer: a propensity-score matched analysis of NSQIP database. Ann Surg Oncol 2019;26:2001-10.

93. Zhang Y, Han Y, Gan Q, Xiang J, Jin R, et al. Early outcomes of robot-assisted versus thoracoscopic-assisted Ivor Lewis esophagectomy for esophageal cancer: a propensity score-matched study. Ann Surg Oncol 2019;26:1284-91.

94. Chao YK, Hsieh MJ, Liu UH, Liu HP. Lymph node evaluation in robot-assisted versus video-assisted thoracoscopic esophagectomy for esophageal squamous cell carcinoma: a propensity-matched analysis. World J Surg 2018;42:590-98.

95. van der Sluis PC, Ruurda JP, van der Horst S, Verhage RJ, Besselink MG, et al. Robot-assisted minimally invasive thoraco-laparoscopic esophagectomy versus open transthoracic esophagectomy for resectable esophageal cancer, a randomized controlled trial (ROBOT trial). Trials 2012;13:230.

96. van der Sluis PC, van der Horst S, May AM, Schippers C, Brosens LAA, et al. Robot-assisted minimally invasive thoracolaparoscopic esophagectomy versus open transthoracic esophagectomy for resectable esophageal cancer: a randomized controlled trial. Ann Surg 2019;269:621-30.

97. Lee L, Sudarshan M, Li C, Latimer E, Fried Gm, et al. Cost-effectiveness of minimally invasive versus open esophagectomy for esophageal cancer. An Surg Oncol 2013;20:3732-9.

98. Parameswaran R, Veeramootoo D, Krishnadas R, Cooper M, Berrisford R, et al. Comparative experience of open and minimally invasive esophagogastric resection. World J Surg 2009;33:1868-75.

99. Ecker BL, Savulionyte GE, Datta J, Dumon KR, Kucharczuk J, et al. Laparoscopic transhiatal esophagectomy improves hospital outcomes and reduces cost: a single-institution analysis of laparoscopic-assisted and open techniques. Surg Endosc 2016;30:2535-42.

100. Liu CY, Lin CS, Shih CS, Huang YA, Liu CC, et al. Cost-effectiveness of minimally invasive esophagectomy for esophageal squamous cell carcinoma. World J Surg 2018;42:2522-9.

101. Dhamija A, Dhamija A, Hancock J, McCloskey B, Kim AW, et al. Minimally invasive oesophagectomy more expensive than open despite shorter length of stay. Eur J Cardiothorac Surg 2014;45:904-9.

102. Fu SJ, Ho VP, Ginsberg J, Perry Y, Delaney CP, et al. Complications, not minimally invasive surgical technique, are associated with increased cost after esophagectomy. Minim Invasive Surg 2016;2016:7690632.

103. Yanasoot A, Yolsuriyanwong K, Ruangsin S, Laohawiriyakamol S, Sunpaweravong S. Costs and benefits of different methods of esophagectomy for esophageal cancer. Asian Cardiovasc Thorac Ann 2017;25:513-7.

104. Klapper JA, Hartwig MG. Robotic esophagectomy: a better way or just another way? J Thorac Dis 2017;9:2328-31.

105. Sarkaria IS, Rizk NP, Goldman DA, Sima C, Tan KS, et al. Early quality of life outcomes after robotic-assisted minimally invasive and open esophagectomy. Ann Thorac Surg 2019;108:920-28.

106. Fujiwara H, Shiozaki A, Konishi H, Kosuga T, Komatsu S. Perioperative outcomes of single-port mediastinoscope-assisted transhiatal esophagectomy for thoracic esophageal cancer. Dis Esophagus 2017;30:1-8.

107. Fujiwara H, Shiozaki A, Konishi H, Otsuji E. Transmediastinal approach for esophageal cancer: a new trend toward radical surgery. Asian J Endosc Surg 2019;12:30-6.

108. Mori K, Aikou S, Yagi K, Nishida M, Mitsui T, et al. Technical details of video-assisted transcervical mediastinal dissection for esophageal cancer and its perioperative outcome. Ann Gastroenterol Surg 2017;1:232-7.

109. Nakauchi M, Uyama I, Suda K, Shibasaki S, Kikuchi K, et al. Robot-assisted mediastinoscopic esophagectomy for esophageal cancer: the first clinical series. Esophagus 2019;16:85-92. 